\title{
PREPARACION PSICOPROFILACTICA PARA EL PARTO E HIPNOSIS
}

Doctores Juan José Báez* y Orlando Marincolo

Durante nuestra práctica en la preparación psicoprofiláctica para el parto en el Instituto de Maternidad Alberto Peralta Ramos encontramos desde un comienzo y mucho más a medida que iba aumentando nuestra experiencia, cierta similitud entre ella y la hipnosis. Este trabajo no tiene otra finalidad que exponer a la consideración de los señores colegas las reflexiones que motivan la preparación de más de 3.000 embarazadas.

El procedimiento psicoprofiláctico nació en el año 1920 iniciando su estudio dos psiquiatras, Platonov y Velvosky, el primero de los cuales, junto con Nicolaiev, creó un método basado en la sugestión y la hipnosis, que aun cuando sus resultados fueron auspiciosos, fue abandonado para dar paso Nicolaiev con otros obstetras al plan de la psicoprofilaxis.

$\mathrm{El}$ auge de la hipnosis como terapéutica en las distintas ramas de la medicina periódicamente alcanza a la obstetricia para hacer luego una silenciosa desaparición. En este movimiento pendular en la actualidad el hipnotismo vuelve a interesar por sus resultados halagadores.

\section{Psicoprofilaxis}

La preparación psicoprofiláctica de la embarazada es una parte de la higiene del embarazo, que consiste en darle una educación para el momento del parto, en los tres últimos meses de la gravidez.

Con él se obtiene un beneficio inmediato, pues corrige los desajustes emocionales en temperamentos predispuestos antes de la gestación o predispuestos durante la gestación por desequilibrios hormonales propios de este estado.

Elabora nuevos reflejos condicionados creando en forma activa focos positivos, al aprender lo que ha ocurrido y ocurre durante el embarazo y lo que ocurrirá en el parto.

Hace disminuír o desaparecer las viviencias molestas de la gravidez y su tendencia a transferirlas al momento del parto como un acto de peligro. El temor es un fenómeno racional que tiene la virtud de admitir un peligro in-

Tel Instituto de Maternidad Alberto Peralta Ramos. Buenos Aires, Argentina. 
minente; debe desaparecer cuando se elimina la causa que lo engendró. Es fundamental investigar y poner en evidencia la causa del miedo.

$\mathrm{Si}$ aclarada la causa no desaparece el miedo, es que estamos frente a la ansiedad, y en este caso la embarazada debe pasar a la consulta del médico psicólogo.

Si el peligro es imaginario y va acompañado de opresión precordial con manifestaciones motoras, está constituída la angustia y también debe enviarse la paciente al médico psicólogo.

La primera clase tan importante para explicar los fundamentos del método, con vocabulario claro y simple, origina en la grávida un entusiasmo y una responsabilidad personal en el éxito del procedimiento. Se debe motivar de acuerdo al tipo temperamental, y ese interés acrece a medida que transcurre la preparación, aun aquellas que por su personalidad acuden sin un convencimiento profundo.

La segunda clase consiste en dar nociones de anatomía y fisiología del aparato genital femenino, la fecundación, la evolución del embarazo, los períodos del parto y la visión de dispositivos mostrando el parto de una preparada. En última instancia toda enseñanza es una sugestión. A ello debemos añadir que la conversación sostenida deja una impresión fuerte y duradera que sugestiona indirectamente.

El aprendizaje de la relajación neuromuscular durante el transcurso de las sesiones en las que se valora su progreso, reforzada por la práctica diaria en su domicilio para obtener su dominio en el período de dilatación, es un nuevo reflejo condicionado fundamental en la psicoprofilaxis.

Durante las sesiones de relajación el instructor actúa de manera decidida, tranquila y segura, con suave tono de voz, serena, suave, sugestiva y firme. Se sugiere la indoloridad asociada a la relajación realizada con sus propios esfuerzos o bajo la dirección del médico o de la partera y a medida que el preparador va teniendo más experiencia aun sin darse cuenta sugestiona.

Queda por demostrar si la práctica del jadeo de tipo costal superior y cómputo de las respiraciones determina una alcalosis que sea responsable de trastornos metabólicos de las neuronas que aumenten el umbral de la sensibilidad. Este condicionamiento es privativo de la psicoprofilaxis.

La embarazada aprende que tanto la relajación como el jadeo deben ser hechos durante la contracción uterina del trabajo de parto. Este concepto debe ser bien fijado desde un principio si se quiere aumentar las probabilidades de un buen pronóstico. Debemos tener la seguridad de que la grávida ha aprendido cuándo se inicia, cuánto dura y cómo termina el período de dilatación.

La gimnasia es creadora de focos positivos. No solamente fortalece los músculos y facilita el movimiento de las articulaciones de la pelvis sino que estimula la psiquis dándose una sensación optimista de seguridad. Conoce la grávida cómo puede colaborar en forma efectiva y cuánto dura el período expulsivo. Además, tiene un concep- 
to claro de la episiotomía, su indoloridad por el uso de la anestesia local que lo comprueba con la visita a las puérperas que hayan seguido la psicoprofilaxis.

La visita a la Sala de Partos y un simulacro del período expulsivo dan un beneficio tan evidente que ellos solos justifican la educación de la embarazada.

\section{Hipnosis.}

La hipnosis es la sugestión ejercida por el médico sobre la gestante por medio de la palabra. Elman prefirió llamarla relajación médica para no despertar las resistencias que aquella palabra todavía produce.

En la hipnosis también el médico crea un reflejo condicionado para el momento del parto, pero con cierto grado de obnubilación mental, traducido por tranquilidad e indiferencia al medio que la rodea con excepción de la voz del instructor, que tiene grabada en su corteza cerebral, obedeciéndole plenamente porque sabe que le redunda en beneficio.

La mayor dificultad reside no sólo en que todas las embarazadas no pueden ser hipnotizadas, sino que tampoco los médicos están preparados, y esta preparación es más complicada que para la psicoprofilaxis.

La primera sesión debe constituír un encuentro agradable y placentero entre el instructor y la grávida.

La técnica de la relajación muscular es análoga a la de la psicoprofilaxis y no la hemos de repetir. Siguiendo la ta- bla de orientación y control del grado de profundidad de Duprat, bastan algunas manifestaciones objetivas del grado profundo para apreciar el estado de hipnosis. Relajamiento muscular, pesadez general y cierre de los párpados de grado muy leve, catalepsia general y movimientos automáticos de grado mediano.

Puntos comunes entre psicoprofilaxis y la hipnosis.

La metodología seguida por nosotros en psicoprofilaxis en donde hay siete clases teórico-prácticas incluyendo a la relajación, evidencia nuestra enseñanza como una antesala de la hipnosis.

El local de que disponemos para los ejercicios guarda los siguientes requisitos, que son los mismos que aconsejamos para repetir la práctica domiciliaria. Lugar adecuado a donde no lleguen ruidos o murmullos que perturben, con cierto grado de penumbra para que las concurrentes puedan concentrar su atención en la palabra del preparador.

La primera y la segunda clase sirven para iniciar una relación amena entre el instructor y la grávida.

La relajación muscular sigue una técnica análoga en ambos casos. Una leve diferencia es que no se le hace fijar la mirada en un punto determinado de la habitación, ni en un objeto, ni en los ojos del preparador.

La relajación en la psicoprofilaxis puede interpretarse como un hipnotismo vígil en el cual la embarazada no está indispensablemente dormida, vale decir que, estando despierta, está hipnotizada. 
Los medicamentos que se utilizan pueden incluírse en ambos métodos, pues tienen por finalidad facilitar la relajación muscular y ser ataráxicos. Deben tener moderada influencia sobre la corteza cerebral, no traer acostumbramiento, no alargar el parto, no ser tóxico, elevar el umbral del dolor.

\section{Ventajas e inconveniencias de ambos métodos.}

En el procedimiento psicoprofiláctico la grávida ha elaborado nuevos reflejos condicionados, mejorando todos sus mecanismos físicos y psíquicos para el momento del parto. En la hipnosis el condicionamiento se logra con cierto grado de obnubilación mental.

La psicoprofilaxis tiene ventaja sobre la hipnosis en que las clases se pueden dictar en conjunto y no es imprescindible la presencia del instructor en el momento del parto.

No obstante, debemos aclarar que en la psicoprofilaxis también se puede presentar la pérdida de control, y si no se encuentra el instructor presente existe la posibilidad de que no se reencuentre con lo aprendido. Parecería que se hubiere hecho más hipnosis que psicoprofilaxis y que interviene en forma preponderante el tipo temperamental de la mujer.

La hipnosis tiene la ventaja de la impresión profunda con que se han grabado en su mente las palabras del preparador durante las sesiones de condicionamiento, no existiendo prácticamente la posibilidad de desequilibrio si está presente en el parto.

No hablaremos de los factores de fracaso de ambos métodos.

\section{Hipnosis después del aprendizaje psicoprofiláctico.}

Si durante la relajación muscular, en el transcurso de las clases, o en sus prácticas domiciliarias, observamos signos objetivos de hipnosis, es evidente que estamos frente a una embarazada con susceptibilidad para ella.

$\mathrm{Si}$ la grávida manifiesta voluntad o disposición por la hipnosis, pues tiene cierto grado de sugestabilidad que el preparador acentuó durante las sucesivas sesiones, aumentando su confianza en él, está en condiciones óptimas para asistir a sesiones de hipnotismo. Será conveniente la realización previa de las pruebas de susceptibilidad, que sin entrar a considerar cada una de ellas, diremos que entre las más importantes contamos con el balanceo postural, entrecruzamiento de los dedos de las manos o adhesión de las manos de la paciente con el preparador, ya sea por relajación o contracción muscular.

Una vez finalizado el curso de psicoprofilaxis, concurrirá a clases de hipnosis, que se dictarán dos veces por semana, con una duración de una hora cada vez. Estas clases no deben ser forzosamente individuales.

De esta manera el condicionamiento durante la psicoprofilaxis es la primera etapa para la hipnosis.

En el período de dilatación se aprovecha ese estado de obnubilación mental para darle órdenes de ejecutar lo aprendido durante su educación psicoprofiláctica. Y durante el período expulsivo se aprovecha la relajación del intervalo de la contracción para darle órdenes aprendidas en el simulacro de expulsión. 